\title{
Caring for Women with Abortion Complications In Ethiopia: National Estimates and Future Implications
}

By Hailemichael Gebreselassie, Tamara Fetters, Susheela Singh, Ahmed Abdella, Yirgu Gebrehiwot, Solomon Tesfaye, Takele Geressu and Solomon Kumbi

Hailemichael Gebreselassie is senior research advisor, Ipas Africa Alliance, Nairobi, Kenya.

Tamara Fetters is senior associate, Ipas, Chapel Hill, NC, USA. Susheela Singh is vice president for research, Guttmacher Institute, New York. Ahmed Abdella and Yirgu Gebrehiwot are consultant obstetrician/ gynecologists, and Solomon Kumbi is associate professor of obstetrics and gynecology-all at Addis Ababa

University, Addis Ababa, Ethiopia. At the time this research was conducted, Solomon Tesfaye and Takele Geressu were research associate and

senior associate, respectively, Ipas Ethiopia, Addis Ababa.

\begin{abstract}
CONTEXT: Ethiopia liberalized its abortion law in 2005, primarily to reduce the incidence of unsafe abortion. However, little is known about the current extent and consequences of unsafe abortion.
\end{abstract}

\begin{abstract}
METHODS: Data were collected in 2007-2008 on 1,932 women seeking postabortion care at a nationally representative sample of 344 public and private health facilities. In addition, staff respondents at 337 facilities provided information on their facility's services and caseload. These data were used to examine patterns of abortion-related morbidity and treatment and to generate national estimates.
\end{abstract}

RESULTS: Almost 58,000 women sought care for complications of induced or spontaneous abortion in 2008. Threequarters of the women received care in government facilities. Forty-one percent had moderate or severe morbidity, such as signs of infection, that were likely related to an unsafe abortion. Seven percent of all women had signs of a mechanical injury or a vaginally inserted foreign body. More than 13,000 women seeking postabortion care required a hospital stay of at least 24 hours. The case fatality rate among women seeking postabortion care in public hospitals, where the most serious complications were seen, was 628 per 100,000.

CONCLUSIONS: Postabortion care and safe abortion services should be further expanded and strengthened to make these services more accessible and affordable, which in turn may ease the financial burden on hospitals and allow the resources currently required for postabortion care to be used for other health needs. Ensuring that all women know that safe abortion is available and legal for many indications will further reduce morbidity from unsafe abortions. International Perspectives on Sexual and Reproductive Health, 2010, 36(1):6-15

Unsafe abortion continues to be common in Africa, despite global efforts to improve postabortion care and advance reproductive rights, rising contraceptive use and a continentwide trend toward easing abortion restrictions. ${ }^{1-3}$ Defined as a procedure for terminating an unwanted pregnancy that is performed by persons lacking the necessary skills or in an environment lacking minimal medical standards (or both), unsafe abortion remains a leading cause of maternal mortality and morbidity in Africa, accounting for an estimated $14 \%$ of maternal deaths. The World Health Organization (WHO) estimates that every year, nearly 5.5 million African women have an unsafe abortion; as many as 36,000 of these women die from the procedure, while millions more experience short- or long-term morbidity. ${ }^{1}$

Ethiopia is a representative case. The second most populous country in Africa, Ethiopia is home to about 77 million people, most of whom live in rural areas. The country's maternal health statistics are grim: One in 27 women die from complications of pregnancy or childbirth, ${ }^{4}$ the number of maternal deaths is fifth highest in the world 5 and the maternal mortality ratio, estimated to be 673 per 100,000 live births, is extremely high. ${ }^{6}$ The extent to which unsafe abortion contributes to these maternal deaths is unknown.

Death and disability from unsafe abortion can be prevented in three ways: by preventing unintended pregnan- cy, treating the complications of women who seek postabortion care or providing a safe, legal alternative to unsafe abortion. Until 2005, the Ethiopian penal code permitted abortion only to save the pregnant woman's life or to preserve her health from grave danger, and required diagnosis and certification by a medical practitioner, as well as confirmation by an obstetrician/gynecologist. In 2005, the penal code was amended to permit abortion under a much broader set of circumstances: in the case of rape, incest or fetal impairment; if pregnancy continuation or birth would endanger the health or life of the woman or fetus; if the woman has physical or mental disabilities; and if the woman is a minor who is physically or mentally unprepared for childbirth. ${ }^{7}$ In most cases, a woman's statement is sufficient to establish the legal indication for, and allow her to obtain, the abortion. Although legal reform took place five years ago, social norms regarding abortion are just beginning to change, and the expansion of safe abortion services has progressed slowly. Because recent studies, both in and outside of Africa, suggest that legal reform is not enough to eliminate unsafe abortion, researchers and policymakers have emphasized the need to reduce abortion stigma, inform citizens of their rights and address inequities in abortion accessibility. 1,2,5,7,8

Unsafe abortion poses burdens not only for women and their families, but also for the country's health system. 
While the Ethiopian government has begun to make safe, legal abortion available throughout the country, it has struggled with the burden of caring for women with complications of unsafe abortions. Postabortion care services have improved, ${ }^{9-11}$ but deaths and suffering from unsafe abortion continue to occur, even though they are preventable with the appropriate information, education, training, technology and political commitment. Treating the complications of unsafe abortion often requires surgery, expensive drugs and supplies, and prolonged hospital stays, ${ }^{12-16}$ and the cost of treating a septic abortion is estimated to be four times that of an assisted delivery. ${ }^{12}$ In some developing countries, treating complications of unsafe abortion consumes up to $60 \%$ of the total annual budget for gynecologic care. ${ }^{14}$ According to one estimate, the annual cost of treating abortion complications in Ethiopiaincluding expenditures incurred by either women or the health system-was almost US\$8 million in 2000. ${ }^{17}$

The penal code changes in Ethiopia provide a unique opportunity to document the extent and consequences of unsafe abortion; such research provides a baseline from which future changes in morbidity can be assessed. The objective of this research was to estimate the demand for postabortion care and describe morbidity from complications of unsafe abortion and miscarriage in Ethiopia in 2008, as well as to examine the severity of postabortion cases treated in a nationally representative sample of hospitals and other health facilities. This research is the first nationwide study on abortion-related morbidity in Ethiopia.

\section{METHODS}

The analysis described here was part of a larger project to assess the incidence, severity and consequences of safe and unsafe abortion in Ethiopia. Only the methods and procedures relevant to the estimation of unsafe abortion and spontaneous abortion (miscarriage), or the treatment of women with abortion complications, are described below. A complete description of methods and results pertaining to the estimation of the incidence of induced abortion is provided in the article by Singh et al. in this issue. ${ }^{18}$

\section{Sampling and Weighting}

The sampling frame consisted of public, private and nongovernmental organization (NGO) providers of maternal health services. A national sample of health facilities was selected from Ethiopia's 11 administrative areas-nine regions and two city administrations (one of which is the capital city of Addis Ababa). Although the government is the primary provider of health care, the number of privatesector providers has been increasing rapidly, particularly for abortion care. A small but growing number of NGOs also provide abortion-related care.

Public-sector facilities include referral hospitals, zonal and district hospitals, and health centers with satellite health posts and stations. Private-sector facilities can be categorized as hospitals, special clinics (such as maternal and child health centers) or private clinics (high-, medium-
TABLE 1. Number of eligible and sampled facilities, and number and percentage of participating facilities, by survey - all according to facility type, Ethiopia, 2007-2008

\begin{tabular}{|c|c|c|c|c|c|c|c|}
\hline \multirow[t]{2}{*}{ Facility type } & \multicolumn{3}{|l|}{ All } & \multicolumn{2}{|c|}{$\begin{array}{l}\text { Morbidity } \\
\text { study }\end{array}$} & \multicolumn{2}{|c|}{$\begin{array}{l}\text { Health facility } \\
\text { survey }\end{array}$} \\
\hline & $\begin{array}{l}\text { No. of } \\
\text { eligible } \\
\text { facilities }\end{array}$ & $\begin{array}{l}\% \\
\text { sampled }\end{array}$ & $\begin{array}{l}\text { No. of } \\
\text { sampled } \\
\text { facilities }\end{array}$ & $\begin{array}{l}\text { No. of } \\
\text { partici- } \\
\text { pating } \\
\text { facilities }\end{array}$ & $\begin{array}{l}\% \\
\text { partici- } \\
\text { pating }\end{array}$ & $\begin{array}{l}\text { No. of } \\
\text { partici- } \\
\text { pating } \\
\text { facilities }\end{array}$ & $\begin{array}{l}\% \\
\text { partici } \\
\text { pating }\end{array}$ \\
\hline Public hospitals & 94 & 100 & 94 & 90 & 96 & 89 & 95 \\
\hline $\begin{array}{l}\text { Public health centers } \\
\text { NGO reproductive }\end{array}$ & 597 & 30 & 177 & 158 & 89 & 154 & 87 \\
\hline health clinics & 24 & 100 & 24 & 24 & 100 & 24 & 100 \\
\hline Private/NGO hospitals & 39 & 100 & 39 & 39 & 100 & 39 & 100 \\
\hline $\begin{array}{l}\text { High-level private } \\
\text { clinics }\end{array}$ & 144 & 40 & 59 & 33 & 56 & 31 & 53 \\
\hline Total & 898 & 44 & 393 & 344 & 88 & 337 & 86 \\
\hline
\end{tabular}

Note: $\mathrm{NGO}=$ Nongovernmental organization.

and low-level facilities). Most of the facilities that are run by NGOs are hospitals and clinics.

The sampling universe was created by preparing lists of all facilities in the country that offer reproductive health services. Eligible facilities were those thought to have the potential to provide treatment for abortion complications or postabortion care, induced abortion services (as permitted by law), or labor and delivery services. Health posts, health stations, and medium- and low-level private clinics were excluded because they were expected to provide limited or no abortion services. Members of the study team then visited each region or city administration to validate and refine these lists.

The final sampling frame consisted of 898 facilities (Table 1). A stratified, single-stage systematic random sample without replacement was selected to ensure adequate representation of each type of facility that could be providing abortion care and of each region of the country. Eligible facilities were stratified by region (11 strata) and facility type (three strata); the latter were sampled in different proportions according to the importance of the facility type in providing postabortion care and to the number of facilities of that type. Thus, within each region, we selected $100 \%$ of public, private and NGO hospitals, as well as all NGO facilities that provide reproductive health services; $30 \%$ of public health centers; and $40 \%$ of high-level private clinics.

Overall, 393 facilities were chosen for inclusion. Selected facilities were invited to participate by the research team in collaboration with Regional Health Bureau staff. Forty-nine facilities did not participate. In 20 cases, security concerns (e.g., regional instability) or other reasons related to physical inaccessibility precluded participation; 20 additional facilities did not provide abortion services and were unwilling to send a representative to attend the required training, and seven others were never located or were misidentified in the list. The remaining two facilities refused to participate. Facilities that did not participate were not replaced; thus, the final sample consisted of 344 facilities, a participation rate of $88 \%$. However, no abortion cases were documented in 36 participating facilities during data collection. 
Weights were calculated for each stratum on the basis of the sample fraction and the level of nonresponse; the data were adjusted for strata that contained few eligible or participating facilities. For eight of the 33 combinations of region and facility type, the number of participating facilities was not large enough to represent the facility type in that area. In these cases, the facilities were regrouped with others of the same type and from similar regions, and the weights recalculated. This resulted in 21 strata used for the analysis. Sampled facilities that did not provide abortion care during the study period (but did so at other times) were included in the analysis.

\section{Data Collection}

Data for this study were collected in two related but separate surveys. First, prospective abortion-related morbidity data were obtained on the symptoms and clinical management of all women who presented for abortion care in the sampled health facilities during the 28-day study period. Second, at each facility, a respondent knowledgeable about maternity or abortion care completed a Health Facilities Survey questionnaire concerning the facility's services and caseload. All data collection occurred between November 2007 and March 2008.

- Prospective morbidity data collection. Our analysis was based in part on the prospective morbidity methodology, a technique originally used to determine whether abortion complications were likely related to an unsafe abortion or to a miscarriage. The methodology, which was developed by a WHO task force, has been adapted and used to measure the severity of abortion-related complications in countries as diverse as South Africa, Cambodia and Kenya. 8,19-23 For this study, we reviewed data collection instruments from Kenya and Cambodia and revised them on the basis of input obtained from a panel of experts and investigators. The resulting instruments were pilot tested and then further revised.

A provider (gynecologist, physician, midwife or health officer) from each participating facility was trained to extract case information on abortion clients using the revised instrument. Each provider completed two days of training, including sessions on terminology, data collection practice, study components and objectives, confidentiality and ethical considerations.

During a period of 28 consecutive days, each provider used the standardized form to collect data on all women presenting to his or her facility with complications from an incomplete, missed, inevitable, complete or septic abortion before the 28th week of gestation. * Data collectors did not differentiate between complications resulting from un-

*An incomplete abortion is one in which fetal or placental components remain in the uterus; it may be the result of a spontaneous abortion or complications from an induced abortion. In a missed abortion or an inevitable abortion, the fetus is no longer developing or viable; the former term is used if no bleeding or cramping is occurring, while the latter is used if the women presents with an open cervix and vaginal bleeding. In a complete abortion, all products of conception have been expelled. An induced or spontaneous abortion is considered septic if retained tissue has become infected.
TABLE 2. Percentage distribution of women seeking postabortion care, by selected characteristics, prospective morbidity study, Ethiopia, 2007-2008

\begin{tabular}{lrr} 
Characteristic & No. & $\%$ \\
\hline Site where care sought & & \\
Public hospital & 1,194 & 62 \\
Public health center & 348 & 18 \\
Private/NGO facility & 390 & 20 \\
& & \\
Referred to higher level of care & 121 \\
Yes & 1,811 & \\
No &
\end{tabular}

Marital status

Married

Single

Cohabiting

Separated/widowed/divorced

$1,567-81$

$275 \quad 14$

$45 \quad 3$

Age

$\leq 17$

$18-24$

$25-29$

30-34

$\geq 35$

62

18

20

Residence

Urban/periurban

Rural

Education

None

Some primary school

Some secondary school

Some postsecondary school

No. of previous pregnancies

2

3

$\geq 4$

Previous miscarriage

Yes

Previous abortion

Yes

Pregnancy followed contraceptive failuret Yes

Estimated gestational age

First trimester

Second trimester

Tried to end pregnancy

Yes

No

Totals

na

100

†Client reported using modern contraceptives to prevent the pregnancy for which she was seeking postabortion care. ‡Includes 15 cases with missing values that were imputed to first trimester. Note: All numbers and percentages are unweighted and unless otherwise noted exclude missing responses. $\mathrm{NGO}=$ nongovernmental organization. $n a=$ not applicable.

safe abortions and those from miscarriages. Information was gathered on demographic characteristics, self-reported induction attempts, reproductive history, vital signs, symptoms found on physical exam, symptoms for which the woman came to the facility and clinical management. 
The patients were not interviewed directly, although the providers asked questions concerning demographic characteristics during the consultation. The flow of the form approximated that of the woman's care to minimize provider effort and improve data quality. Patient identifiers were removed at the time of collection to protect confidentiality. Study team members and regional supervisors visited each site at least twice during the data collection period, and the latter monitored data collection and checked records for completeness.

- Health Facilities Survey. During the data collection period for the prospective morbidity survey, we surveyed respondents from the same facilities regarding abortion services in their facility. In most cases, these respondentsfacility managers, supervisors or providers working in abortion service delivery-were the same individuals who collected the morbidity data. Each respondent completed a questionnaire that included questions concerning training of personnel, facility infrastructure and equipment, and abortion caseloads. In particular, they were asked to estimate the number of postabortion cases the facility treated in an average month and the number it had treated in the past month. Respondents from 337 facilities completed questionnaires, representing $86 \%$ of selected facilities. Data were entered and checked using Epidata version 3.1 and then transferred to Stata version 9.2 and SPSS version 17.0 for analysis.

\section{Data Analysis}

A limitation of using the prospective morbidity methodology to calculate national estimates of abortion complications is that the number of actual postabortion cases may be underreported. ${ }^{24,25}$ To address this issue, we also utilized the two provider estimates of postabortion caseloads when calculating national estimates; the provider figures were often higher than the numbers of abortion cases observed in the prospective morbidity methodology. These three figures-average monthly cases, last month's cases, and actual cases recorded during data collectionwere examined for outliers and anomalies. They were then annualized (the provider estimates were multiplied by 12 and the 28-day morbidity survey data by 13.04) and summed, and the arithmetic means were used for producing weighted caseload estimates.

We used methods of variance estimation for survey data to account for the stratified sampling design; standard errors were calculated using the Taylor-series approximation. Adjusted chi-square statistics and their corresponding $\mathrm{p}$ values were used to identify bivariate associations; statistical significance was defined as $\mathrm{p}<.05$.

For nearly all variables, rates of nonresponse were lower than 5\%; unless otherwise indicated, analyses for each variable excluded cases with missing data for that measure. All percentages are weighted to account for missing responses; however, we present unweighted descriptive data for the morbidity survey sample to allow a more thorough assessment of the results. Although missing data
TABLE 3. Percentages (and 95\% confidence intervals) of women seeking postabortion care who had selected medical signs or died, and percentage distribution of women according to severity of morbidity-all by type of facility

\begin{tabular}{|c|c|c|c|c|}
\hline Measure & $\begin{array}{l}\text { All } \\
(\mathrm{N}=57,964)\end{array}$ & $\begin{array}{l}\text { Public } \\
\text { hospital } \\
(\mathrm{N}=20,198)\end{array}$ & $\begin{array}{l}\text { Public } \\
\text { health center } \\
(\mathrm{N}=23,317)\end{array}$ & $\begin{array}{l}\text { Private/ } \\
\text { NGO facility } \\
(\mathrm{N}=14,449)\end{array}$ \\
\hline$\geq 1$ sign of infection $\dagger$ & $24(21-27)$ & $25(21-28)$ & $26(20-32)$ & $19(13-25)$ \\
\hline$\geq 1$ sign of physical interference $\neq$ & $7(5-9)$ & $8(5-11)$ & $7(3-11)$ & $4(1-7)$ \\
\hline$\geq 1$ sign of organ failure $\S$ & $2(1-3)$ & $2(1-4)$ & $3(1-4)$ & $1(0-2)$ \\
\hline Died from unsafe abortion & $0.2(0.1-0.4)$ & $0.6(0.2-1.1)$ & 0.0 & 0.0 \\
\hline \multicolumn{5}{|l|}{ Severity of morbidity } \\
\hline Low & $59(55-63)$ & $58(52-64)$ & $55(48-62)$ & $71(63-78)$ \\
\hline Moderate & $14(11-16)$ & $12(8-17)$ & $15(11-20)$ & $11(6-17)$ \\
\hline Severe & $27(24-31)$ & $30(26-34)$ & $30(23-35)$ & $18(13-23)$ \\
\hline
\end{tabular}

†Sepsis, shock, peritonitis, tetanus or offensive products of conception. $¥$ Mechanical injury to or foreign body in the vagina, cervix, uterus or intra-abdominal area. §Disseminated intravascular coagulation, coma, respiratory distress or other signs. Notes: All percentages are weighted and exclude missing responses. Categories of morbidity sequelae are not mutually exclusive. $\mathrm{NGO}=$ nongovernmental organization.

were uncommon, imputation was deemed necessary for one variable, gestational age; for the 15 respondents who were missing data on this variable, gestational age was imputed to the first trimester on the basis of the clinical data. To calculate complication rates and ratios for the Ethiopian population, we used data from the 2007 national census and adjusted it for growth. ${ }^{26}$ The ethical committee of the Ethiopia Science and Technology Agency reviewed and granted ethical clearance for the research.

\section{RESULTS}

\section{Respondent Characteristics}

Information on the characteristics and postabortion care of 1,932 women was collected during the study period. Most postabortion clients ( $81 \%$ ) were married (Table 2). Their mean age was 28; only one in 10 was an adolescent (not shown). More than half (57\%) lived in an urban or periurban area. A substantial proportion (42\%) reported having no formal education. Nearly all had already been pregnant at least once, and most at least twice. Half of the women told providers that they had had a previous miscarriage, and a third (35\%) reported terminating a past pregnancy. About one-quarter (24\%) reported that they had been using a modern contraceptive method when they conceived their current pregnancy; contraceptive use was highest among women who sought care in a private facility (not shown). Thirty-eight percent of women were seeking care for complications in the second trimester of pregnancy, and 14\% said they had already tried to end their pregnancy. Women in their second trimester of pregnancy were disproportionately likely to be from rural areas $(p=0.002$; not shown). Seven of the women seeking postabortion care died (not shown).

\section{Symptoms and Severity}

- Symptoms. A fourth of women had a highly (9\%) or moderately (14\%) elevated temperature, an initial sign of infection (not shown). Just 3\% had a more serious symp- 
TABLE 4. Number of women seeking postabortion care; number and percentage distribution of these women by severity of morbidity; and percentage of these women who were hospitalized_-all according to region

\begin{tabular}{|c|c|c|c|c|c|c|c|c|}
\hline \multirow[t]{2}{*}{ Region } & \multirow{2}{*}{$\frac{\text { All }}{\text { No. }}$} & \multicolumn{2}{|l|}{ Severe } & \multicolumn{2}{|c|}{ Moderate } & \multicolumn{2}{|l|}{ Low } & \multirow{2}{*}{$\begin{array}{l}\% \\
\text { hospitalized }\end{array}$} \\
\hline & & No. & $\%$ & No. & $\%$ & No. & $\%$ & \\
\hline Addis Ababa & 7,233 & 868 & $12^{* * *}$ & 651 & 9 & 5,714 & 79 & $13(9-18)^{* *}$ \\
\hline Other & 50,731 & 14,816 & 29 & 7,052 & 14 & 28,863 & 57 & $24(20-27)$ \\
\hline Dire Dawa/Harari & 3,671 & 918 & 25 & 220 & 6 & 2,533 & 69 & $31(15-48)$ \\
\hline SNNP & 10,896 & 2,724 & 25 & 1,416 & 13 & 6,756 & 62 & $20(13-27)$ \\
\hline Oromiya & 20,310 & 6,093 & 30 & 2,843 & 14 & 11,374 & 56 & $26(19-33)$ \\
\hline Amhara & 9,242 & 2,865 & 31 & 1,386 & 15 & 4,991 & 54 & $14(8-19)$ \\
\hline ASBG & 3,274 & 1,048 & 32 & 786 & 24 & 1,440 & 44 & $24(16-33)$ \\
\hline Tigray & 3,338 & 1,168 & 35 & 401 & 12 & 1,769 & 53 & $46(34-58)$ \\
\hline
\end{tabular}

**Percentage for Addis Ababa is significantly different from percentage for other regions at $p<.01$. ***Percentage distribution by severity of morbidity in Addis Abada is significantly different from that in other regions at $\mathrm{p}<.001$. Notes: All data are weighted. Hospitalization refers to a stay of at least 24 hours. SNNP= Southern Nations, Nationalities and People's Region. ASBG=Affar, Somali,Benishangul-Gumuz and Gambela.

tom, a pulse of more than 119 beats per minute, which is a precursor to shock (not shown). Women also exhibited other signs of serious morbidity. Nearly one-quarter had at least one sign of infection (Table 3, page 9). Signs of physical interference with the pregnancy, such as the presence of a foreign body or mechanical injury to the vaginal, cervical or uterine area, were present in $7 \%$ of women, including $7-8 \%$ of those treated in public facilities and $4 \%$ of those treated in private ones $(p=.09)$. Two percent of women showed signs of organ failure; these women were more likely to have gone to public facilities than to private facilities for care $(p=.05)$. About $0.2 \%$ of all women died

\begin{abstract}
TABLE 5. Percentages (and 95\% confidence intervals) of women seeking postabortion care who received selected types of care, and percentage distribution of these women by type of provider-all according to type of facility
\end{abstract}

\begin{tabular}{|c|c|c|c|c|}
\hline Measure & $\begin{array}{l}\text { All } \\
(N=57,964)\end{array}$ & $\begin{array}{l}\text { Public } \\
\text { hospital } \\
(N=20,198)\end{array}$ & $\begin{array}{l}\text { Public } \\
\text { health center } \\
(\mathrm{N}=23,317)\end{array}$ & $\begin{array}{l}\text { Private/NGO } \\
\text { facility } \\
(\mathrm{N}=14,449)\end{array}$ \\
\hline Referred elsewhere ${ }^{* * *}$ & $13(9-16)$ & $1(1-2)$ & $27(19-35)$ & $4(1-7)$ \\
\hline \multicolumn{5}{|l|}{ Evacuation performed } \\
\hline Any ${ }^{* * *}$ & $79(75-83)$ & $93(91-95)$ & $59(50-68)$ & $95(92-98)$ \\
\hline Sharp curettaget, ${ }^{* * *}$ & 38 & 54 & 25 & 25 \\
\hline MVA/EVAt, ${ }^{* * *}$ & 56 & 37 & 69 & 72 \\
\hline Other†, $\neq$ & 6 & 9 & 6 & 3 \\
\hline Antibiotics provided & $83(79-87)$ & $85(79-91)$ & $79(73-86)$ & $86(79-93)$ \\
\hline Transfusion administered* & $2(1-3)$ & $4(2-5)$ & $1(0-1)$ & $1(0-2)$ \\
\hline Intravenous fluids given*** & $44(39-49)$ & $66(61-72)$ & $35(27-43)$ & $19(11-26)$ \\
\hline Pain medication given $* * *$ & $54(48-59)$ & $60(51-68)$ & $40(30-50)$ & $71(58-85)$ \\
\hline Hospitalization required $* * *$ & $23(19-26)$ & $43(38-49)$ & $9(5-13)$ & $11(6-16)$ \\
\hline \multicolumn{5}{|l|}{ Evacuation provider $\S, * * *$} \\
\hline Physician & $43(37-49)$ & $68(70-76)$ & $3(1-6)$ & $81(72-90)$ \\
\hline Midlevel provider & $35(30-41)$ & $25(18-32)$ & $55(45-64)$ & $14(6-22)$ \\
\hline Missing & $21(17-26)$ & $7(5-10)$ & $42(33-51)$ & $5(2-8)$ \\
\hline
\end{tabular}

*Percentages differ among facility types at $\mathrm{p}<.05$. ***Percentages differ among facility types at $\mathrm{p}<.001$ †Because of the large number of strata used in the analysis, the standard error estimates for the "other" subcategory are unstable; thus, only point estimates are shown for the three subcategories. \#Includes pitocin, medical methods and manual removal of retained products. §Specialists, general practitioners, residents and interns are considered physicians; nurses, midwives and health officers are midlevel providers. Notes: All percentages are weighted and unless otherwise noted exclude respondents with missing data. Hospitalization refers to a stay of at least 24 hours. $\mathrm{NGO}=$ nongovernmental organization. $\mathrm{MVA} / \mathrm{EVA}=$ manual vacuum aspiration or electric vacuum aspiration. from their complications, all of them at public hospitals. - Severity of morbidity. The symptom severity index used in this research was initially developed as a tool to distinguish miscarriages from unsafely induced abortions. ${ }^{21}$ Self-reports of induction attempts, moderate and severe morbidity, and abortion complications in the second trimester of pregnancy are infrequent among women who have had a miscarriage, but they are strongly associated with attempted unsafe abortion.

In this sample, $14 \%$ of women told their provider that they had done something to try to cause an abortion (either by themselves or with the assistance of another person) prior to seeking postabortion care (not shown). As noted above, $7 \%$ of all women presented with signs of mechanical injury to or foreign bodies in the intrauterine area, an indication of the invasiveness of unsafe abortion procedures. Two percent of all women were found to have a foreign body inserted in their vagina or uterus (not shown).

Almost six in 10 women presenting for postabortion care had symptoms of low severity, as they showed no unusual morbidity other than pain and bleeding (Table 3). However, $41 \%$ of women had either moderate or severe morbidity, indicating that their condition was more serious or deteriorating. Fourteen percent of women were classified as moderately ill, as they had "offensive" products of conception (infected retained products), a slightly elevated temperature $\left(37.3-37.9^{\circ} \mathrm{C}\right)$ or localized peritonitis. The remaining $27 \%$ had severe morbidity-signs of infection, evidence of shock, mechanical or foreign body injury, elevated pulse, organ failure or generalized peritonitis-or died. Seriously ill women (those with moderate or severe morbidity) more often sought care in public facilities than in private ones (42-45\% vs. $29 \%$ ) and were as likely to go to a health center as to a hospital for care (not shown).

- Regional variation in abortion morbidity. Women who sought postabortion care at a facility in Addis Ababa were less likely than those in other regions to have serious complications (Table 4). Only 21\% of women who presented with abortion complications in Addis Ababa had severe or moderate morbidity, compared with $43 \%$ of those who sought care in other parts of the country. The proportion of patients with severe or moderate morbidity was also relatively small in Dire Dawa and Harari (31\%), two highly urban regions where access to safe abortion and private services is above the national norm. The proportion of women with severe morbidity was highest in Tigray (35\%) and in the region encompassing Affar, Somali, Benishangul-Gumuz and Gambela (32\%), the most isolated and rural areas in the country; access to safe abortion, and to health care in general, is poor in these regions.

A further indication of the severity of complications is the proportion of women hospitalized during treatment (i.e., those who required a stay of at least 24 hours). Only $13 \%$ of women seeking care in Addis Ababa were hospitalized, compared with 24\% of those in other areas.

- Service provision and treatment. One-third (34\%) of women seeking postabortion care presented in the second 
trimester of pregnancy (weighted value; not shown); the proportion differed by facility type $(\mathrm{p}<.001)$, ranging from $20 \%$ in private facilities to $30 \%$ in public health centers and $45 \%$ in public hospitals. One-fourth of the women (25\%) said that their pregnancy was the result of contraceptive failure (weighted value; not shown).

The type of care that a woman received often differed according to the type of facility where she received treatment. Most women (75\%) sought care for complications of unsafe abortion or miscarriage at public health facilities (not shown). Thirteen percent of all women, and $27 \%$ of those who sought care at health centers, required referral to a higher-level health facility (Table 5). Women were more likely to receive a uterine evacuation at a private health facility (95\%) or a public hospital (93\%) than at a public health center (59\%). Providers in public hospitals were more likely than those in public health centers or private facilities to use sharp curettage in the first trimester (18\% vs. $1 \%$; not shown), even though the method is not a WHO-recommended technique. Conversely, aspiration methods-such as manual vacuum aspiration or, in a very few cases, electric vacuum aspiration-were used much more often in public health centers and private health facilities than in hospitals (69-72\% vs. 37\%). Sixty-eight percent of first-trimester postabortion care procedures in the country were performed with aspiration methods (not shown). Medical abortion using mifepristone or misoprostol, although becoming more common globally, was rare in any type of facility ( $1 \%$ of cases overall); however, pitocin (a synthetic form of the hormone oxytocin used to induce labor) was administered in 5\% of cases, primarily to women in their second trimester who were treated in hospitals. Manual removal of retained products of conception was used in seven cases, probably because manual vacuum aspiration was unavailable (not shown).

More than three-quarters (83\%) of all women received antibiotics (Table 5). Only $2 \%$ received blood transfusions, although $44 \%$ of women needed intravenous fluids for stabilization. Slightly more than half of women (54\%) received medication for pain during the course of their treatment; women in health centers were less likely than women treated elsewhere to receive such medication.

The majority of patients seeking postabortion care were treated and discharged on the same day (i.e., as outpatients), but 23\% remained at the facility for at least 24 hours. A substantial proportion of postabortion care was delivered by physicians (43\%), although midlevel providers, such as nurses, midwives and health officers, treated more than one-third (35\%) of women. However, a large number of responses for this variable were missing, particularly in health centers, where information on the provider was unavailable for $42 \%$ of patients.

\section{Annual Incidence of Postabortion Treatment}

We estimate that 57,964 women with postabortion complications were treated in Ethiopian health facilities in 2008 (Table 6). Almost three in four, or an estimated
TABLE 6. Selected estimates (and 95\% confidence intervals) of the number of women with abortion-related complications, hospitalizations and deaths, and related statistics, Ethiopia, 2008

Measure

No.

Women receiving postabortion care

Any

Public facilities

Private/NGO facilities

$57,964(50,847-65,081)$

$43,515(35,557-51,475)$

$14,449(9,528-19,369)$

Women treated for moderate/severe complications

$23,765(21,447-26,084)$

Women hospitalized for complications

$13,332(11,593-15,071)$

Complications per 1,000 women of reproductive age

3.49

Complications per 100 live births

1.96

Deaths per 100,000 women treated in public hospitals

for postabortion complications

$628(163-1,092)$

Deaths in health facilities due to unsafe abortion

$100(24-175)$

Notes: Hospitalization refers to a stay of at least 24 hours. Rates and ratios are calculated using data on the numbers of women of reproductive age and births in Ethiopia in 2007, adjusted for population growth (reference 26).

43,515 women, sought care from public-sector hospitals or health centers. About one-third of women seeking postabortion care, or 19,708 women, were already in their second trimester of pregnancy when they came to the health facility (not shown). More than $40 \%$, or 23,765 women, were severely or moderately ill, and 13,332 required a facility stay of at least 24 hours.

There were 16,582,708 women of reproductive age and 2,964,323 births in Ethiopia in 2007. ${ }^{26}$ After adjusting these figures for population growth, we estimate that 3.5 per 1,000 women of reproductive age were treated for complications of unsafe abortion and miscarriage in health facilities in 2008, and that 2.0 women were treated for abortion complications for every 100 live births. In addition, we estimate that 100 women died in health facilities from abortion complications in 2008, with 87 of the deaths occurring among women in the second trimester of pregnancy (not shown). The case fatality rate among women treated for abortion complications in public hospitals (where all of the deaths were reported) was 628 per 100,000 postabortion complication cases, or $0.6 \%$ of all women who received postabortion care in these hospitals.

\section{DISCUSSION}

Access to high-quality postabortion care should be considered a right for all women. According to our study, almost 58,000 Ethiopian women sought postabortion care in 2008 and more than 13,000 had hospital stays of 24 hours or longer for abortion complications, requiring valuable bed space and scarce human and financial resources. Most of these women were married and had had at least two prior pregnancies; thus, their injuries and any subsequent morbidity affected not just themselves but their households.

Compared with the general population of Ethiopian women of reproductive age, women obtaining postabor- 
tion care in this study were older, better educated and more likely to have children. ${ }^{6}$ The average age of women in this study was 28; most likely, many had been sexually active for at least a decade. One-third of the women reported having had a previous abortion, indicating the need for a strong postabortion family planning program; many of these unsafe abortions could have been prevented with appropriate postabortion counseling and contraceptive provision. However, one in four women reported that their pregnancy was the result of contraceptive failure (i.e., they were using contraceptives at the time they became pregnant), a proportion much higher than the national contraceptive prevalence rate of $14 \%$ for modern methods. ${ }^{4} \mathrm{~A}$ shift to more effective contraceptive methods and a stronger emphasis on postabortion contraceptive provision would reduce rates of contraceptive failure and unintended pregnancy in this group.

Fourteen percent of women said that they had already tried to end their pregnancy before seeking postabortion care, even though many of these women would have been eligible for a safe, legal abortion. Although women may be more likely to report a termination attempt to their health care providers than to standard interviewers, ${ }^{15,20,25}$ pervasive stigma against abortion-as well as a lack of knowledge that abortion is legal-may have kept even more women from disclosing a clandestine abortion attempt. In addition, women who desired to terminate an unwanted pregnancy may not have been able to do so safely because of the attitudes of their partner or family members or the belief that a safe abortion is expensive or unavailable. To reduce the prevalence of abortion-related morbidity, clandestine abortions need to be eliminated through the prevention of unintended pregnancy or the provision of safe abortion services.

The findings on clinical management and care by facility type indicate that public-sector facilities are carrying most of the resource burden for abortion complications in Ethiopia. Government health facilities remain the main source of care for women who are poor, live in underserved areas or have severe injuries. In fact, three-quarters of women seeking postabortion care-and almost $90 \%$ of severely or moderately ill women-were treated at government facilities. Public hospitals are still managing most postabortion cases in Ethiopia, even though $73 \%$ of women did not have severe morbidity and probably could have been treated in a primary care facility if trained providers and adequate equipment had been available.

In many instances, however, such providers and equipment may not be available. More than one in four women who sought treatment in a health center were referred to a hospital for further care, possibly because some health centers are unable to manage abortion patients, especially those who are severely ill. The high proportion of missing data on the type of provider who performed the uterine evacuations in health centers is unusual; it may indicate that the providers were untrained or unauthorized to perform these procedures and thus reluctant to admit having done so. In- creasing the capacity of lower-level facilities to manage cases with low morbidity would reduce costs and treatment delays, and relieve the burden on referral hospitals. Improving accessibility of postabortion services throughout the public sector would almost certainly save lives.

The risks of unsafe abortion depend on the provider's skill and facilities, the method used, the general health of the woman and the stage of pregnancy. ${ }^{1}$ Although we did not ask providers to distinguish between complications of unsafe abortion and those of miscarriage, the data suggest that a substantial proportion of the women they treated had had an unsafe abortion. More than one-quarter of women who presented for postabortion care in our study were severely ill by the time they reached the health facility; most of these women showed signs of sepsis, an unlikely complication for a woman having a miscarriage. In addition, $7 \%$ of all women showed signs of physical interference with the pregnancy-an inserted object, marks from medical instruments used in a botched abortion, or other physical damage to the vaginal or cervical area. Signs of physical interference and organ failure were most commonly found among women who sought care in public facilities; contributing factors include the fact that public hospitals are more likely than private facilities to treat severe complications and offer postabortion care at very low cost. Another explanation is that most private health facilities in Ethiopia are located in urban and periurban areas, where women may have access to a wider variety of abortion providers and to better information from peers and others, allowing them to obtain safer, less invasive procedures.

The prevalence of high-severity abortion-related morbidity was lower in Addis Ababa than in the remainder of the country ( $12 \%$ vs. $29 \%$ ), most likely due to better access to safe abortion services. Many facilities in Addis Ababa now provide pregnancy terminations with few restrictions. A qualitative, community-based study conducted in 2007 among ethnic Guraghes living in rural areas of the Southern Nations, Nationalities and People's Region south of Addis Ababa found that although women recognize the need for abortion services and express sympathy for women who wish to obtain a safe abortion, they are unaware of how to get one, thinking that such services are available only in Addis Ababa and are prohibitively expensive. ${ }^{27}$

This study was not designed to provide an overall measure of abortion-related maternal mortality. Rather, it provides an estimate of the number of abortion-related maternal deaths that occurred in health facilities in a one-year period. The estimated number of deaths in all facilities in 2008 (100) is consistent with the 13 deaths reported from 15 public hospitals during a six-month period in $2000^{17}$ and with reports provided by Health Facility Survey respondents about abortion-related deaths in facilities in the previous year. However, on the basis of data from this study and other sources, ${ }^{2,26}$ we estimate that fewer than $4 \%$ of women who die from unsafe abortion do so in health facilities. This is not unexpected, given the low levels of health care coverage in some parts of the country 
and of health care utilization in general; for example, only $6 \%$ of births took place in health facilities in $2005 .{ }^{6}$

Case fatality rates provide another measure of the overall severity of postabortion cases. The case fatality rate among women treated at public hospitals was 628 deaths per 100,000 postabortion complication cases-substantially higher than the WHO estimates of 350 deaths per 100,000 unsafe abortions in developing regions, but much lower than the rate of 1,209 deaths per 100,000 women treated for postabortion complications documented in the study of 15 public hospitals. ${ }^{17}$ The latter study is not entirely comparable with ours, as it examined tertiary hospitals that were likely treating the most serious complications, whereas our study included all 94 public hospitals in Ethiopia. However, although design differences between these two studies probably account for some of the disparity in the case fatality rate, it is likely that a portion represents a real decline.

\section{Comparison of Abortion Morbidity in Three African Nations}

The prospective morbidity methodology has been used nationally in two other African countries, Kenya and South Africa. In a 2002 study conducted in a nationally representative group of government hospitals in Kenya, a country with a highly restrictive abortion law, the proportion of all women with high-severity complications (28\%) was similar to that in our study $(27 \%) .{ }^{23}$ However, the morbidity rate in Kenya likely would have been lower if private hospitals and health centers had been included in the analysis (as in our study), because women with more serious complications tend to go to public hospitals if they can. In South Africa, researchers examined abortion complications in a nationally representative sample of public hospitals in 1994, when the country's abortion law was still restrictive, and in 2000, after the new constitution allowed abortion on demand. $8,22,24,28$ The proportion of postabortion patients with high-severity morbidity declined from $17 \%$ in 1994 to $10 \%$ in $2000.8,22$ The latter figure is far lower than the $27 \%$ documented in our study about three years after Ethiopia reformed its abortion law. The decline observed in South Africa suggests that a similar trend may occur in Ethiopia.

Rates of morbidity and hospitalization related to unsafe abortion may have fallen in some countries since the early 1990s in response to increased availability of safe abortion services. ${ }^{3}$ A recent Ethiopian study reviewed the type and severity of abortion complications in a referral hospital in Addis Ababa between 2003 and 2007, a period that began before reform of the abortion law and ended two years after passage of the new law. ${ }^{29}$ The authors found nonsignificant decreases in the number of abortion complications and in the abortion-related maternal mortality ratio; they suggested that morbidity may have begun to decline in the hospital because providers were receiving better training in postabortion care, and because women had increased access to such care and were undergoing fewer invasive clandestine procedures than in the past. ${ }^{29}$ Although one indicator of morbidity, the proportion of women with signs of physical interference, increased from 3.3\% to $4.7 \%$ in the study, and the case fatality rate rose as well, in both years the number of such injuries was too small to yield firm conclusions on these trends. In the study conducted in 15 hospitals around the country, 12\% of women seeking postabortion care showed signs of lacerations, perforation or mechanical injury to the intra-abdominal area. ${ }^{17}$ This proportion was much larger than the levels documented in the 2003-2007 study or in the present national study, where only $7 \%$ of women had signs of physical interference. It seems likely that the most severe complications from the most invasive unsafe abortion procedures and their consequences are generally declining in Ethiopia as access to safe abortion and postabortion care improves.

Thirty-four percent of all women who sought care in health facilities in 2008 for complications of an unsafe abortion or miscarriage were in their second trimester of pregnancy, when a spontaneous abortion is uncommon and an unsafe abortion attempt can be particularly dangerous. These women face high risks of present and subsequent morbidity. In the 2002 Kenyan study, women in the second trimester had elevated odds of presenting with moderate or severe morbidity and, as in this study, accounted for almost all abortion-related deaths. ${ }^{23}$ We found that women in the second trimester tended to be from rural areas, suggesting that rural women have relatively poor access to safe, legal abortion services, and that they face challenges in obtaining timely postabortion care. Providing women with better access to postabortion care and safe abortion services, and ensuring that these services are well-known in communities, should result in simpler, safer abortion procedures at earlier gestations and in more timely receipt of postabortion care.

\section{Limitations and Conclusions}

This research has some limitations. Although we attempted to capture every case of abortion complications, some cases may not have been recorded during data collection. When we compared the numbers of cases observed in the prospective morbidity methodology survey with the caseload estimates from providers at the same facilities, the caseloads in the former survey were often lower than provider estimates. However, by using two very different methods for measuring the number of women treated for abortion complications, this study addressed limitations of both methodologies and provided a more accurate estimate.

Another shortcoming in our research design is that the estimates are limited to women with abortion-related complications who succeeded in obtaining services in a health facility. Although health care access is improving in Ethiopia, the country has faced challenges in increasing health care utilization. ${ }^{30}$ For example, the proportion of women who give birth with the assistance of a skilled attendant is among the lowest in Sub-Saharan Africa. ${ }^{6}$ If this pattern of low utilization is similar for all maternal health care, including postabortion services, then the facility-based data presented here would represent only a small proportion of the 
women with morbidity and mortality from abortion. Other women may die without seeking care for their symptoms, die before they are able to obtain care, seek care from traditional practitioners or not seek care at all. However, because of the strong postabortion care program established by the government and NGO partners over the past decade, the proportion of women with abortion complications who obtain postabortion care may be higher than the proportion of pregnant women who deliver in health facilities. ${ }^{10}$

Finally, analyses by type of facility are necessary to examine the distribution and availability of services, but may be misleading. Women in need were turned away at some facilities because the sites lacked the capacity to provide necessary care. Some serious cases treated at hospitals may have been referrals from lower-level facilities. This study did not attempt to trace each point of care-seeking, and thus a small number of women who were referred from one facility to another may have entered the sample more than once. We decided to include all individual cases, as stabilization, treatment and resource utilization were different in each facility.

The results presented here provide a snapshot of abortion morbidity in a country that is making the transition from having a restrictive abortion law to allowing greater access to safe, legal abortion services. Policymakers can use these findings to strengthen the case for making access to safe abortion a public health priority for all women. Increased provision of contraceptive services would help couples avoid unintended pregnancies and abortions. Repeating this study in five years might yield very different results if the availability of safe abortion services continues to improve, and if access to modern contraceptives reduces unmet need and helps couples avoid unwanted pregnancies. This research provides a baseline against which to compare future findings.

Unlike some African nations, Ethiopia appears to be on course to reduce abortion-related morbidity and mortality. Yet, the elimination of unsafe abortion remains elusive. Postabortion care and safe abortion services should be further expanded and strengthened in public health centers and private health facilities; making these services more accessible (e.g., by providing them in primary care facilities) and affordable can ease the burden on hospitals and allow the resources currently required for postabortion care to be used for other health promotion and prevention efforts. Use of vacuum aspiration and medical abortion methods can also improve quality of care and reduce costs. Programs to reduce unintended pregnancy through provision of contraceptive services are urgently needed, as are efforts to make postabortion contraceptives available not only to women in cities but also those in rural areas, where this study found great need. Finally, building a society free of abortion-related stigma, where each woman knows the legal grounds for abortion and any woman who qualifies knows that it is her right to have a safe and affordable pregnancy termination in her own community, will require persistence and determination from a diverse coalition of partners.

\section{REFERENCES}

1. World Health Organization (WHO), Unsafe Abortion: Global and Regional Estimates of the Incidence of Unsafe Abortion and Associated Mortality in 2003, fifth ed., Geneva: WHO, 2007.

2. Sedgh G et al., Induced abortion: estimated rates and trends worldwide, Lancet, 2007, 370(9595):1338-1345.

3. Grimes DA et al., Unsafe abortion: the preventable pandemic, Lancet, 2006, 368(9550):1908-1919.

4. Population Reference Bureau (PRB), 2008 World Population Data Sheet, Washington, DC: PRB, 2008.

5. WHO, Maternal Mortality in 2005: Estimates Developed by WHO, UNICEF, UNFPA and the World Bank, Geneva: WHO, 2005

6. Ethiopian Central Statistical Agency and ORC Macro, Ethiopia Demographic and Health Survey 2005, Addis Ababa, Ethiopia: Central Statistical Agency; and Calverton, MD, USA: ORC Macro, 2006.

7. Ethiopian Ministry of Health, Technical and Procedural Guidelines for Safe Abortion Services in Ethiopia, Addis Ababa, Ethiopia: Ministry of Health, 2006

8. Jewkes R et al., Prevalence of morbidity associated with abortion before and after legalization in South Africa, BMJ, 2002, 324(7348): $1252-1253$

9. Jeppsson A, Tesfu M and Bohmer L, Magnitude of abortion-related complications in Ethiopian health facilities: a national assessment, East African Medical Journal, 1999, 76(10):547-551.

10. Fetters T, Tesfaye $S$ and Clark KA, An assessment of postabortion care in three regions in Ethiopia, 2000 to 2004, International Journal of Gynecology and Obstetrics, 2008, 101(1):100-106

11. Gebreselassie H and Fetters T, Responding to Unsafe Abortion in Ethiopia: A Facility-Based Assessment of Postabortion Care Services in Public Health Sector Facilities in Ethiopia, Chapel Hill, NC, USA: Ipas, 2002

12. Konje JC, Obisesan KA and Ladipo AO, Health and economic consequences of septic induced abortion, International Journal of Gynecology and Obstetrics, 1992, 37(3):193-197.

13. Kay BJ et al., An analysis of the cost of incomplete abortion to the public health sector in South Africa-1994, South African Medical Journal, 1997, 87(4):442-447.

14. Johnston HB, Gallo MF and Benson J, Reducing the costs to health systems of unsafe abortion: a comparison of four strategies, Journal of Family Planning and Reproductive Health Care, 2007, 33(4):250-257.

15. Henshaw SK et al., Severity and cost of unsafe abortion complications treated in Nigerian hospitals, International Family Planning Perspectives, 2008, 34(1):40-50.

16. Vlassoff $\mathrm{M}$ et al., Economic impact of unsafe abortion-related morbidity and mortality: evidence and estimation challenges, IDS Research Report, Brighton, UK: Institute of Development Studies, 2008, No. 59.

17. Mekbib T, Gebrehiwot Y and Fantahun M, Survey of unsafe abortion in selected health facilities in Ethiopia, Ethiopian Journal of Reproductive Health, 2007, 1(1):28-43.

18. Singh $S$ et al., The estimated incidence of induced abortion in Ethiopia, 2008, International Perspectives on Sexual and Reproductive Health, 2010, 36(1):16-25.

19. Jewkes R et al., Why are women still aborting outside designated facilities in metropolitan South Africa? BJOG, 2005, 112(9):12361242

20. Fetters T et al., Abortion-related complications in Cambodia, BJOG 2008, 115(8):957-968.

21. Figa-Talamanca I et al., Illegal abortion: an attempt to assess its cost to the health services and its incidence in the community, International Journal of Health Services, 1986, 16(3):375-389.

22. Rees $\mathrm{H}$ et al., The epidemiology of incomplete abortion in South Africa, South African Medical Journal, 1997, 87(4):432-437.

23. Gebreselassie $\mathrm{H}$ et al., The magnitude of abortion complications in Kenya, BJOG, 2005, 112(9):1229-1235. 
24. Jewkes RK et al., Methodological issues in the South African incomplete abortion study, Studies in Family Planning, 1997, 28(3):228234.

25. Rossier C, Estimating induced abortion rates: a review, Studies in Family Planning, 2003, 34(2):87-102.

26. Ethiopian Population Census Commission, Summary and Statistical Report of the 2007 Population and Housing Census: Population Size by Age and Sex, Addis Ababa, Ethiopia: United Nations Population Fund, 2008 .

27. Hemmings J et al., Ethiopian Women's Perspectives on Reproductive Health: Results from a PEER Study in the Guraghe Zone, London: Options Consultancy Services, 2008.

28. Dickson KE et al., Abortion service provision in South Africa three years after liberalization of the law, Studies in Family Planning, 2003, 34(4):277-284.

29. Gebrehiwot Y and Liabsuetrakul T, Trends of abortion complications in a transition of abortion law revisions in Ethiopia, Journal of Public Health, 2009, 31(1):81-87.

30. Ethiopian Ministry of Health, Health and Health Related Indicators, Addis Ababa, Ethiopia: Ministry of Health, 2007.

\section{RESUMEN}

Contexto: Etiopía liberalizó su ley de aborto en 2005, ante todo para reducir la incidencia del aborto inseguro. Sin embargo, poco se sabe sobre el alcance y consecuencias del aborto inseguro.

Métodos: En 2007-2008, se obtuvo datos sobre 1,932 mujeres que buscaban atención por complicaciones de un aborto inducido o espontáneo, en una muestra representativa a nivel nacional de 344 instituciones de salud públicas y privadas. Adicionalmente, empleados de 337 instituciones proporcionaron información sobre los servicios de sus instituciones y casos atendidos. Estos datos se usaron para examinar patrones de morbilidad y tratamiento relacionados con el aborto y para generar estimaciones nacionales.

Resultados: En 2008, casi 58,000 mujeres buscaron atención por complicaciones de aborto inducidos o espontáneos. Tres cuartas partes de las mujeres recibieron atención en instituciones de gobierno. Cuarenta y un por ciento de las mujeres tuvieron sintomas moderados o muy graves, como signos de infección, que probablemente estaban relacionados con un aborto inseguro. Siete por ciento de todas las mujeres tuvieron signos de lesión mecánica o de un cuerpo extraño insertado en la vagina. Más de 13,000 mujeres que buscaron atención postaborto necesitaron permanecer en la institución al menos 24 horas. La tasa de casos fatales en mujeres que recibieron atención postaborto en hospitales públicos, en donde fueron observadas las complicaciones más graves, fue de 628 por 100,000. Conclusiones: Los servicios de atención postaborto y de aborto seguro deben expandirse y fortalecerse aún más para hacer que estos servicios sean más accesibles y económicos; lo que, a su vez, puede disminuir su carga financiera en los hospitales y permitir que los recursos que actualmente se requieren para atención postaborto sean usados para otras necesidades de salud. Asegurar que todas las mujeres sepan que el aborto seguro está disponible y es legal para muchas indicaciones, reducirá aún más la morbilidad de los abortos inseguros.

\section{RÉSUMÉ}

Contexte: L'Éthiopie a libéralisé sa loi sur l'IVG en 2005, principalement pour réduire l'incidence de l'avortement non médicalisé. On en sait cependant peu sur l'étendue et les conséquences de celui-ci.

Méthodes: Les données ont été collectées en 2007-2008 concernant 1.932 femmes venues chercher des soins post-avortement dans un échantillon nationalement représentatif de 344 établissements de santé publics et privés. De plus, les témoins privilégiés de 337 établissements ont fourni une information sur les services et le charge de cas d'avortement de leur établissement. Ces données ont permis l'examen des tendances de la morbidité et du traitement relatifs à l'avortement, ainsi qu'à la production d'estimations nationales.

Résultats: Près de 58.000 femmes ont cherché à se faire soigner pour complications d'avortement en 2008. Trois quarts d'entre elles ont obtenu des soins dans les établissements de l'état. Quarante et un pour cent présentaient des symptômes moyennement ou fort graves, tels que des signes d'infection, vraisemblablement liés à un avortement non médicalisé. Sur l'ensemble des femmes, $7 \%$ présentaient des signes de lésion mécanique ou d'insertion vaginale d'un corps étranger. Plus de 13.000 femmes venues chercher des soins post-avortement ont nécessité un séjour d'au moins 24 heures. Le taux de mortalité parmi les cas de femmes soignées post-avortement dans les hôpitaux de l'état, où les complications les plus graves ont été observées, s'est avéré de 628 pour 100 mille.

Conclusions: Les services de soins post-avortement et d'avortement médicalisé doivent être étendus et renforcés davantage, pour les rendre plus accessibles et économiquement abordables. La charge financière qui pèse sur les hôpitaux en serait allégée et les ressources actuellement requises pour les soins post-avortement pourraient être affectées à d'autres besoins de santé. En veillant à informer toutes les femmes de la disponibilité légale de l'avortement médicalisé dans de nombreuses circonstances, on réduira davantage aussi la morbidité de l'avortement non médicalisé.

\section{Acknowledgments}

The authors thank the Ethiopian Ministry of Health for endorsing the project, the Regional Health Bureaus for facilitating data collection, and the Ethiopian Public Health Association and the Ethiopian Society of Obstetricians and Gynecologists for their contributions and support as collaborating partners on this project. They also thank Yilma Melkamu and Suzette Audam for their valuable contributions to data collection and processing; the 16 regional coordinators in Ethiopia for their supervision of data collection; Kathryn Anderson Clark for statistical advice; and Heran Belete for administrative and logistical support throughout the project. Finally, the authors are grateful to Saba Kidanemariam, Barbara Crane, Janie Benson and Leila Darabi for reviewing drafts of this article and providing guidance throughout the research process. This research was funded primarily by the Consortium for Research on Unsafe Abortion and its principal donor, the UK Department for International Development. Additional funding was provided by the World Bank. The conclusions expressed are entirely those of the authors.

Author contact:fetterst@ipas.org 